\title{
Regulation of the Mitotic and Meiotic Cell Cycles in the Male Germ Line
}

\author{
Debra J. Wolgemuth, ${ }^{*}{ }^{\dagger}+$ III Erika Laurion, ${ }^{\dagger}$ and Karen M. Lele ${ }^{\dagger}$ \\ *Department of Genetics and Development; ${ }^{\dagger}$ The Institute of Human Nutrition; \\ *Department of Obstetrics and Gynecology; "The Center for Reproductive Sciences; \\ and ${ }^{\|}$The Herbert Irving Comprehensive Cancer Center, Columbia University College of \\ Physicians and Surgeons, New York, New York 10032
}

\begin{abstract}
Mammalian gametogenesis provides a unique system in which to study cell-cycle regulation. Furthermore, understanding the genetic program controlling the mitotic and meiotic divisions of the germ line will provide insight into understanding infertility and new directions for contraception. Male and female germ cells have stages of cell-cycle regulation in common, including a mitotic proliferative stage, entry into meiosis, completion of a reductive division, and entry into a quiescent state awaiting signals at fertilization. However, the timing of these events - and, indeed, even the stage of development at which these events occurs - differs in the two sexes. The genes involved in controlling these specialized mitotic and meiotic cycles of mammalian germ cell differentiation are only now being identified. They include a complex array of kinases, phosphatases, regulatory proteins (e.g., cyclins), and an equally complex array of substrates, including components of the nuclear and cytoplasmic structures involved in cell division. This chapter provides an overview of our current understanding of cell-cycle regulation in mammalian mitotic cells and the importance of restriction points. A summary of observations regarding the expression of various cell-cycle regulatory genes in mouse gametes is provided, along with comments on interesting differences between mitotic and meiotic cells. Finally, the role of the novel A-type cyclin, cyclin A1, during male meiosis is discussed in depth.
\end{abstract}

\section{Introduction}

Understanding the genetic program controlling the mitotic and meiotic divisions of the germ line represents a unique opportunity for providing insight into cell-cycle control in vivo during development and differentiation. Meiosis itself is, of course, restricted to germ line cells and as such represents potential cell-cycle control points that simply do not exist in somatic cells. Furthermore, higher organisms are characterized by sexually dimorphic gametes. Male and female germ cells have stages of cell-cycle regulation in common, including a mitotic proliferative stage, entry into meiosis, completion of a reductive division, and entry into a quiescent state prior to fertilization. However, the timing of these 
events - and, indeed, even the stage of development at which these events occurs - differs in the two sexes (reviewed in Wolgemuth et al., 1995) (Figure 1). For example, female germ cells enter meiosis during fetal development, whereas this is a postnatal event in the male. Once the male germ cell has entered meiosis, the process continues without interruption until the haploid spermatozoon is produced. In contrast, the oocyte is arrested in the diplotene stage of meiotic prophase I, where it can remain for months or years. Following a growth period, the oocyte resumes meiosis, only to arrest at a second point, metaphase II. Fertilization then triggers the completion of meiosis and extrusion of the second polar body. Yet another curiosity of mammalian germ cells is the fact that the two haploid pronuclei commence DNA synthesis independently after fertilization, prior to a fusion event. These and other critical control points in the specialized cell cycles of mammalian germ cells are depicted in Figure 1.

The genetic hierarchy controlling mitosis and meiosis in gamete formation is only recently being elucidated, even in less-complicated systems such as the yeasts. A key player in both mitosis and meiosis is maturation promoting factor

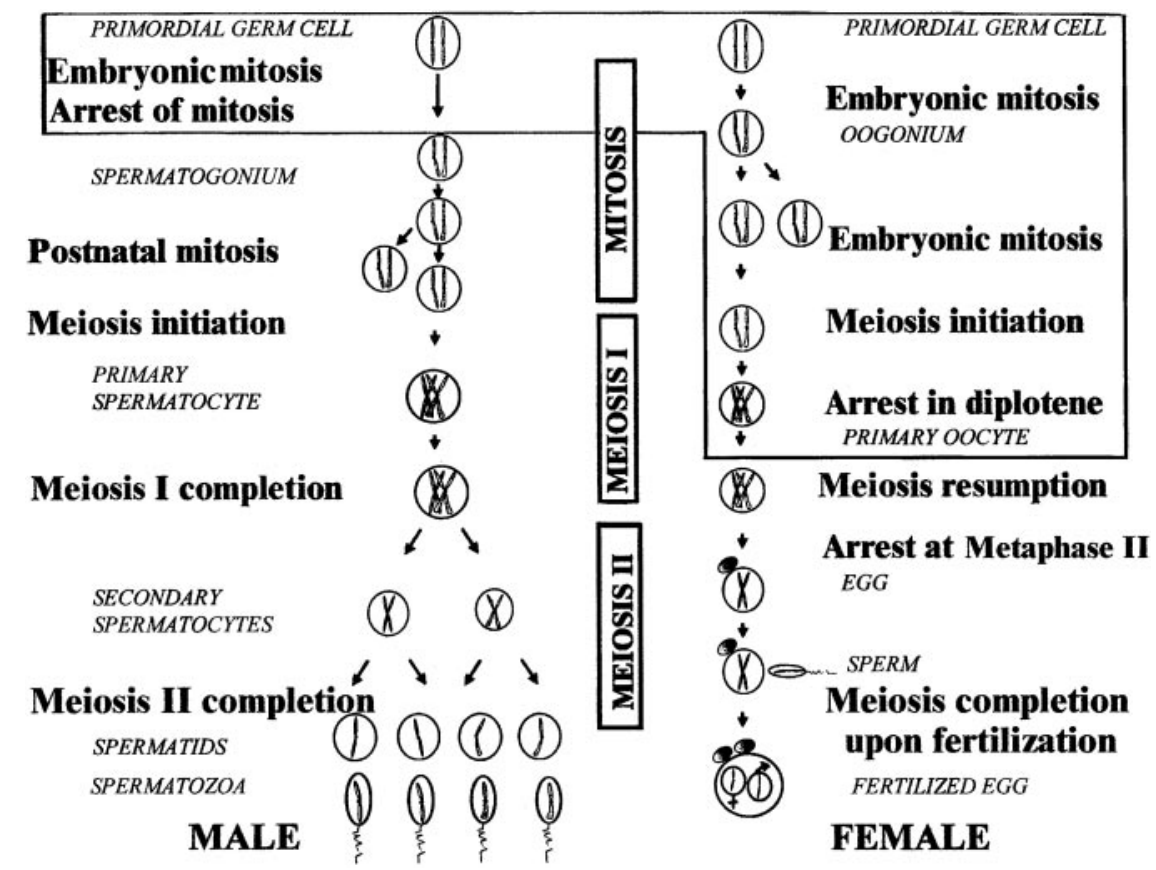

FIG. 1. Flowchart of differences in the cell-cycle progression during mammalian spermatogenesis and oogenesis (Wolgemuth et al., 1995). [Modified from Alberts B, Bray D, Lewis J, Raff M, Roberts K, Watson J 1983 Molecular Biology of the Cell. New York: Garland Publishing, Inc.] 
or M-phase promoting factor (MPF), originally described as an activity found in unfertilized frog eggs capable of inducing germinal vesicle breakdown and resumption of meiosis when injected into immature oocytes (Masui and Markert, 1971). MPF is composed of a regulatory subunit, cyclin $B$, and p34cdc2 (Cdk1), the catalytic serine/threonine protein kinase. These proteins have been detected in all higher eukaryotes examined. Given the high level of conservation of these key molecules across a diverse range of organisms, it is likely that they will also be important for both mitosis and meiosis in mammals, as they are in the yeasts, in which they have been best characterized. However, it is clear that there are control points and "checkpoints" in the cell cycles of higher eukaryotes that do not exist in simpler organisms and that may differ, depending on the developmental and tissue origin of the cells. For example, the oocytes of mammals exhibit unique cell-cycle control points: the signals to enter meiosis are different from those found in yeast, there is an arrest in diplotene of meiosis, and the cell pauses again in metaphase II, awaiting fertilization to complete meiosis (Figure 1). The spermatocyte shares some of these control points but, strikingly, does not normally arrest in either diplotene or at metaphase of meiosis II. It therefore is likely that there will be genes uniquely involved in these regulatory checkpoints that will be distinct from the yeast genes thus far studied.

In this review, we briefly discuss key aspects of cell-cycle control in mammalian cells, most of which have been derived from studies in cultured cells. We then survey what is known about the expression of known mitotic cell-cycle regulators in the testis and ovary, based on previous studies primarily from our lab. We then focus on the A-type cyclins, studies that have occupied much of our attention in the last 5 years and have provided insight into meiosis-specific and sex-specific differences in cell-cycle regulation. Finally, we highlight some of the many unanswered questions regarding the function of the A-type cyclins. These questions are likely to be relevant to other components of the cell-cycle machinery and will provide insight into infertility and possibly identify new targets for contraception.

\section{Overview of the Cell Cycle and Components of the Mammalian Cell-cycle Machinery}

The mammalian mitotic cell cycle involves a sequence of transitions and can be divided into four discrete phases (Figure 2). These stages include S-phase, in which DNA synthesis occurs, and M-phase, in which the cells complete mitosis. Between these stages are two gap (G) phases, G2 (S/M) and G1 (M/S). The progression through these stages is controlled by a series of sequential enzymatic reactions, the activity of which is highly ordered and tightly controlled. Restriction points at the G1/S and G2/M boundaries ensure that the requisite steps have taken place properly (discussed below). The primary enzymatic machinery 


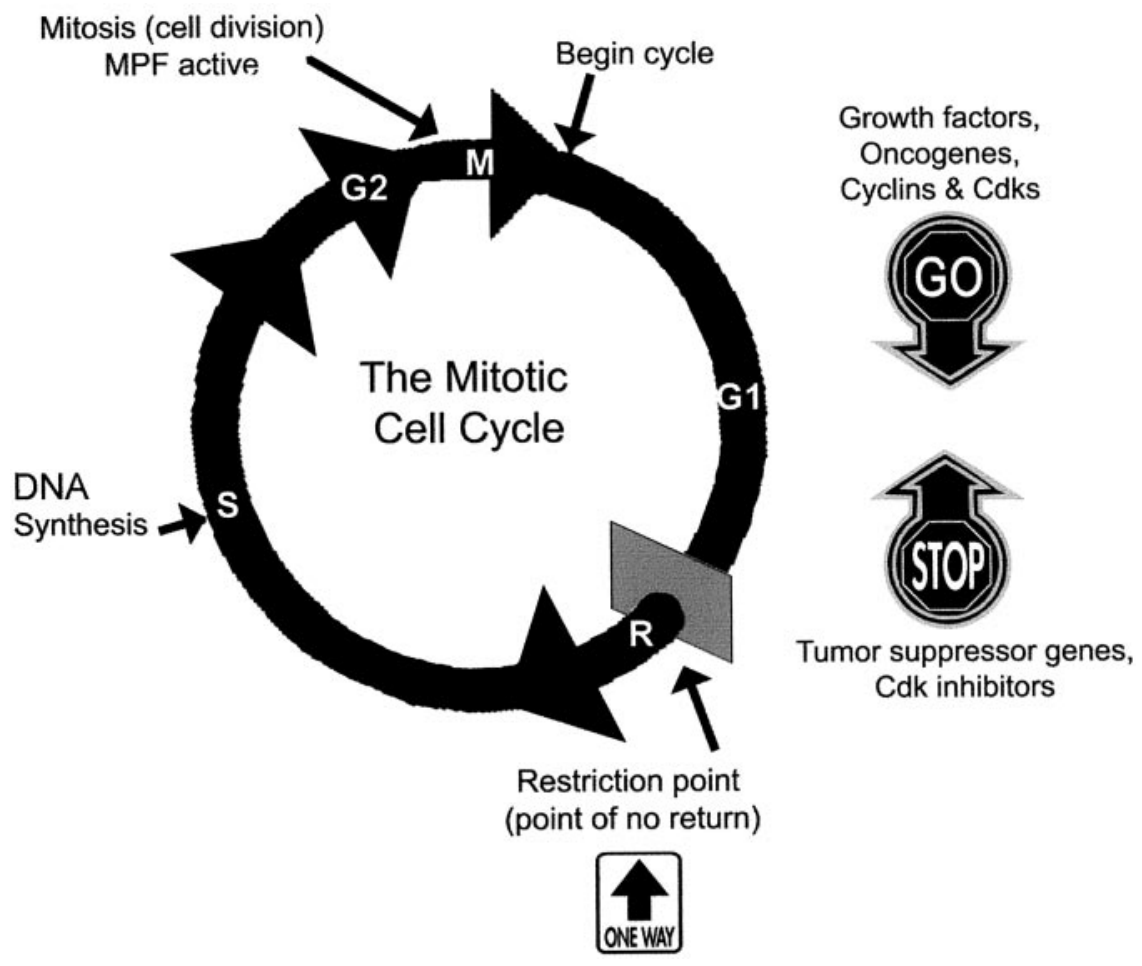

FIG. 2. Cartoon of key players in regulating the mitotic cell cycle.

orchestrating this progression consists of a regulatory subunit (cyclin) and a catalytic subunit, the cyclin-dependent kinase (Cdk).

Cyclins have been identified in a variety of organisms ranging from yeast to man, based on amino acid homology and by functional complementation of yeast cell-cycle mutants. The cyclins have been divided into at least eight classes in higher vertebrates, cyclins $\mathrm{A}$ to $\mathrm{H}$, based on their amino acid similarity and the timing of their appearance during the cell cycle (reviewed in Sherr, 1993; Pines, 1995b; Roberts, 1999). The complexity of the mammalian system is underscored by the existence not only of multiple classes of cyclins but also of multiple members of the A-, B-, and D-type cyclin families. Although their role in mammalian germ cell development is only beginning to be investigated, observations from our lab and others have shown that various cyclins exhibit distinct patterns of expression in the male and female germ cell lineages as well as in the somatic compartments of the gonads (Chapman and Wolgemuth, 1992,1993; Chesnel and Eppig, 1995; Ravnik et al., 1995; Ravnik and Wolgemuth, 1996,1999; Sweeney et al., 1996; Taieb et al., 1997; D. Liu et al., 1998). These 
studies have revealed patterns of cell-type and cell-cycle-stage specificity of in vivo expression of several of the cyclins that had not been detected previously in cultured cell systems (see Section V and Figure 5).

The Cdks are members of a serine/threonine kinase family that share the common properties of a conserved catalytic domain and phosphorylation sites that can modulate their subsequent activity. At least nine distinct Cdks have been identified in mammalian cells and been shown to exhibit differences in their preference for a cyclin partner (Pines, 1995a). The choice of cyclin partner may affect the enzymatic activity of the complex and possibly the substrates as well (Roberts, 1999). There are also Cdk-family members for which no cyclin partners have yet been identified. While they share structural homology to the bona fide Cdks, primarily through their shared PSTAIRE motif (or variations thereof), whether they also participate in cell-cycle regulation remains to be determined.

\section{Modes of Regulation of Activity of Cyclin/Cdk Complexes}

Progression through cell-cycle transitions is due to the sequential appearance of cyclins and activation of their Cdk partner. Several modes of regulating the presence of the cyclins are used, as outlined briefly in the following paragraphs.

\section{A. TRANSCRIPTION}

Cyclin abundance is regulated mainly at the level of transcription and proteolysis. The modes of transcriptional regulation vary among and within the different classes of cyclins. For example, transcription of D-type cyclins is growth factor dependent. When mitogens are withdrawn from cultured cells that have not completed a cell cycle, D-type cyclin mRNA and protein are degraded rapidly and the cells arrest in G1 (Sherr, 1993). Expression of genes for other cyclins and the Cdk1, which function later in the cell cycle, is mediated by elements that resemble, in part, E2F binding sites. The promoter of cyclin E contains a bipartite element named the cyclin E repressor module (CERM). The CERM element binds a protein complex that includes E2F-4 and a pocket protein, which then inhibits transcription (Le Cam et al., 1999). In vivo footprinting revealed that the CERM repressor is occupied only when the gene is not transcribed (in early G1). The onset of expression of the genes for cyclin A2, Cdk1, and cyclin B2 occurs later in the cell cycle than the gene for cyclin E and is mediated by a different bipartite repressor element termed the cell-cycledependent element/cell-cycle genes homology region (CDE/CHR) (Zwicker et al., 1995a; Lange-zu Dohna et al., 2000). The CDE/CHR is occupied when the genes are not transcribed in G1 and a mutation in either the CDE or CHR abolishes repression of corresponding promoter/reporter constructs early in the cell cycle (Zwicker et al., 1995a; Lange-zu Dohna et al., 2000). 


\section{B. TRANSLATION}

Relatively little is known about translational control of cyclin mRNAs, especially in mammalian cells. In budding yeast, initiation of a new cell cycle requires attainment of a critical cell mass and is responsive to the rate of protein synthesis. $\operatorname{Cln} 3$ translation in early G1 is regulated by the cap-binding protein eIF4E, which controls the rate of G1 protein synthesis and is inhibited by rapamycin (Pyronnet et al., 2001). Given the importance of translational regulation of a wide variety of genes during gametogenesis, especially in postmeiotic cells, it would be surprising if mammalian cyclin mRNAs were not regulated, at least in part, at the translational level. In this light, it was interesting to note that only low levels of mouse cyclin B1 were present in postmeiotic spermatids, as compared to meiotically dividing spermatocytes, even though cyclin B1 mRNA was readily detected (Chapman and Wolgemuth, 1994). Furthermore, recent studies on the translation regulatory factor CPEB revealed that it is involved in synapsis and progression through pachytene of meiosis (Mendez and Richter, 2001).

\section{TURNOVER}

The timely degradation of cyclins is equally important to exit a transition and appears to involve a ubiquitin-mediated proteolysis (reviewed in Hershko and Ciechanover, 1998). In this process, a ubiquitin-activating enzyme (E1) activates and transfers ubiquitin to a ubiquitin-conjugating enzyme (E2). E2, along with a substrate recognition protein (E3), assembles a ubiquitin chain on its substrate. Multi-ubiquitinated substrates are rapidly degraded by the 26 s proteasome. There are two types of E3 complexes: the SCF complex and the anaphase-promoting complex (APC). SCF-mediated proteolysis is best studied in yeast. Its substrates include proteins expressed early in the cell cycle, such as the G1 cyclins. Substrates targeted by SCF must first be phosphorylated, suggesting that their stability is controlled by activity of a protein kinase. In mammals, proteolysis of cyclin D1 and cyclin E is controlled by phosphorylation-dependent ubiquitination (Elledge and Harper, 1998). The mitotic cyclins are proteolyzed after APC recognition, which is essential for exit from mitosis. Cyclin A2 is degraded after breakdown of the nuclear envelope (den Elzen and Pines, 2001) and proteolysis of cyclin B is required for exit from M-phase (Gallant and Nigg, 1992).

\section{PHOSPHORYLATION AND DEPHOSPHORYLATION}

The activation state of Cdk complexes is regulated not only by cyclin association but also by $\mathrm{Cdk}$ phosphorylation, which can inhibit or enhance its kinase activity and therefore regulate the timing of Cdk activity (Figure 3). For example, MPF is not active until the G2/M transition, although Cdk1 is present 


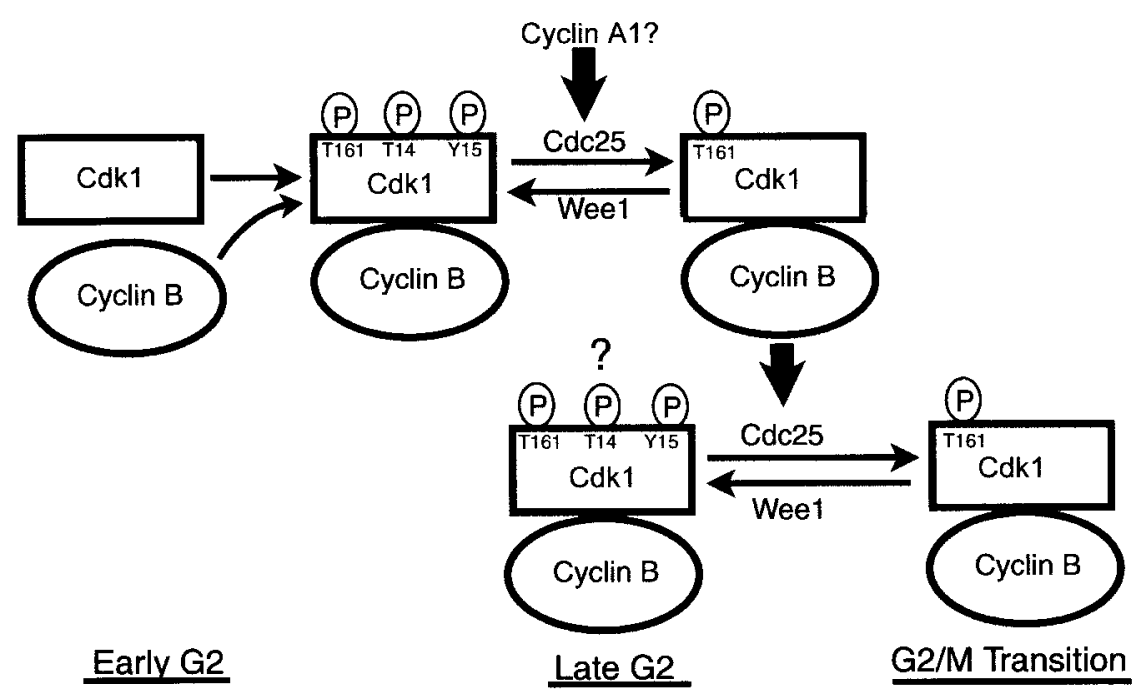

FIG. 3. Cartoon of factors involved in activating and inhibiting MPF.

throughout the cell cycle. In S and G2 phases, Cdk1 complexes with B-type cyclins and becomes phosphorylated on three residues, two of which inhibit activity. At the onset of $\mathrm{M}$ phase, inhibitory phosphorylation is removed by the activity of a protein phosphatase of the Cdc 25 family. In mice, the three Cdc25 genes (Cdc25A, Cdc25B, Cdc25C) are expressed in overlapping but distinct patterns (Kakizuka et al., 1992; Nargi and Woodford-Thomas, 1994; Wu and Wolgemuth, 1995). Cdc25C is activated by phosphorylation by Cdk1/cyclin B1, suggesting that a positive feedback loop exists between $\mathrm{Cdk} 1$ and $\mathrm{Cdc} 25$ (Hoffmann et al., 1993).

\section{E. INHIBITORS}

In mammals and other higher eukaryotes, there are two classes of relatively small (i.e., $16-57 \mathrm{kDa}$ ), tightly binding proteins that function as Cdk inhibitors (CKIs) (reviewed in Sherr and Roberts, 1995,1999). They are grouped according to their structure and their Cdk targets and include the CIP/KIP family consisting of p21CIP1/WAF1, p27KIP1, and p57KIP2 - and the INK family consisting of p16INK4a, p15INK4b, p18INK4c, and p19INK4d. The CKIs appear to exhibit their inhibitory function by binding in a stoichiometric manner, usually to cyclin-Cdk complexes but sometimes to noncomplexed Cdks. The INK family contains ankyrin repeats and binds only to Cdk4 and Cdk6 but not to other Cdks or to the D-type cyclins. The Cip/Kip families are broader with regard to their inhibiting activity, affecting the activity of the cyclin D-, E-, and 
A-type cyclin-dependent kinases. This class contains motifs in their aminoterminal regions that enable them to interact with both cyclin and Cdk proteins. Recent studies suggest that interaction with a Cip/Kip family member may actually positively regulate cyclin D-Cdk complexes but inhibit cyclin A- or E-Cdk complexes (reviewed in Sherr and Roberts, 1999).

\section{F. SUBCELLULAR LOCALIZATION}

A final level of control involves the distribution of the cyclin/Cdk proteins within cells, particularly whether they are in the nuclear or cytoplasmic compartments. For example, cyclin A2 apparently is constitutively nuclear in cultured cells (Pines and Hunter, 1991). However, cyclin B1 accumulates almost exclusively in the cytoplasm and undergoes a striking translocation to the nucleus as the cells enter prophase. This nuclear accumulation of Cdk1-cyclin B appears to be required for mitosis to proceed. Several recent studies have implicated the exclusion of $\mathrm{Cdk} 1 /$ cyclin B in the function of checkpoints that prevent entry into mitosis in the presence of DNA damage (Toyoshima et al., 1998). Nuclear transport factors have been identified that appear to be involved in ferrying some of the cyclins and Cdks in and out of the nucleus. Such factors might have been predicted to exist, since no classic nuclear localization sequences have yet been identified in the primary sequences of any of the vertebrate cyclins or Cdks. As noted, they exhibit striking differences in their subcellular localization (reviewed in Yang and Kornbluth, 1999). In fact, deletion studies have identified sequences in the B-type cyclins that may function as both cytoplasmic-retention sequences and/or nuclear-export sequences (reviewed in Yang and Kornbluth, 1999).

The state of phosphorylation also may be important for the nuclear localization of at least some of the cyclin/Cdk complexes. For example, during meiotic maturation in frog oocytes, phosphorylation of four conserved serine residues in cyclin B1 correlates with the nuclear accumulation and activity of MPF (Li et al., 1995). A model for the role of cyclin B1 localization to the nucleus has been proposed in which phosphorylation of cyclin B1 inhibits its interaction with proteins that appear to favor nuclear export, thus promoting the accumulation of cyclin B1 in the nucleus. While the role of changes in the subcellular distribution of cyclin B1 during meiotic maturation in spermatocytes remains to be demonstrated, we note that cyclin B1 is predominantly cytoplasmic in meiotic prophase cells and shifts to the nucleus just before the entry into the first meiotic division (Liu et al., 2000).

\section{Restriction Points During Mitosis and Meiosis}

Signaling pathways operate at cell-cycle transitions to monitor genomic integrity and the successful completion of upstream events, which ensures 
orderly progress through the cell cycle. In the mitotic cell cycle, response to damaged or improperly replicated or aligned DNA activates pathways that arrest cells at G1-S, G2-M, and at the metaphase-anaphase transition (Figure 2). Recent findings suggest there are two types of cell-cycle checkpoint responses that delay the G1-S transition, both of which target Cdk2 activity. An initial, transient response leads to rapid inhibition of Cdk2 activity due to degradation of Cdc25A (Mailand et al., 2000). A second, sustained response is carried out by p53dependent production of $\mathrm{p} 21$, which binds to and blocks activity of Cdk2/cyclin E complexes (Stewart and Pietenpol, 2001). Arrest at the G2-M phase transition targets MPF by preventing the removal of Cdk1/cyclin B inhibitory phosphorylation. Inhibition of $\mathrm{Cdc} 25 \mathrm{C}$ phosphatase activity is mediated by damage-induced activation of the protein kinase Chk1, which appears to be a primary mechanism of MPF inhibition, as studied in fission yeast (Lopez-Girona et al., 2001) and in human cells (Blasina et al., 1999). Signaling pathways also activate p53, which activates the gene for p21 (Bunz et al., 1998). Interestingly, DNA damage also may repress transcription of genes for cell-cycle regulators. That is, radiationinduced G2 arrest is accompanied by a p53-dependent downregulation of the gene for Cdk1 via the CDE/CHR element (Badie et al., 2000) and the promoters for cyclin B1, cyclin B2, and $\mathrm{Cdc} 25 \mathrm{C}$, which is mediated by NF-Y-binding CAAT boxes (Manni et al., 2001).

The spindle checkpoint is activated at the metaphase-anaphase transition and prevents entry into anaphase until all chromosomes are properly aligned by monitoring microtubule attachment on kinetochores and their tension (Rieder et al., 1994). Components of the spindle checkpoint inhibit activity of APC, which, in the absence of checkpoint activation, degrades proteins, allowing sister chromatid separation and mitosis exit (Clarke and Gimenez-Abian, 2000).

Some evidence exists for the presence of checkpoints in meiotic cell cycles, primarily from studies in yeast. Cells that divide meiotically can arrest in prophase of metaphase I. In yeast, arrest occurs at the pachytene stage of meiotic prophase in response to incomplete chromosome synapsis or recombination (reviewed in Roeder and Bailis, 2000). There may be an analogous checkpoint in mammalian meiotic cells, since failure to enter into meiosis I has been observed when defects occur in prophase (Figure 4; Table I). Male mice lacking genes that function in recombination, DNA repair, or cell-cycle regulation exhibit defects in chromosomal synapsis or recombination during prophase that, unlike observations in yeast, result in apoptosis (Table I). However, it should be noted that the cells arrest at different stages of prophase, suggesting multiple rather than a single checkpoint. In response to low levels of radiation, a G2 delay is observed in spermatocytes that is not observed in spermatocytes that are p53 deficient, suggesting a role for p53 in the process (Schwartz et al., 1999). A spindle checkpoint may be active during meiosis in Drosophila spermatocytes. Entry into 


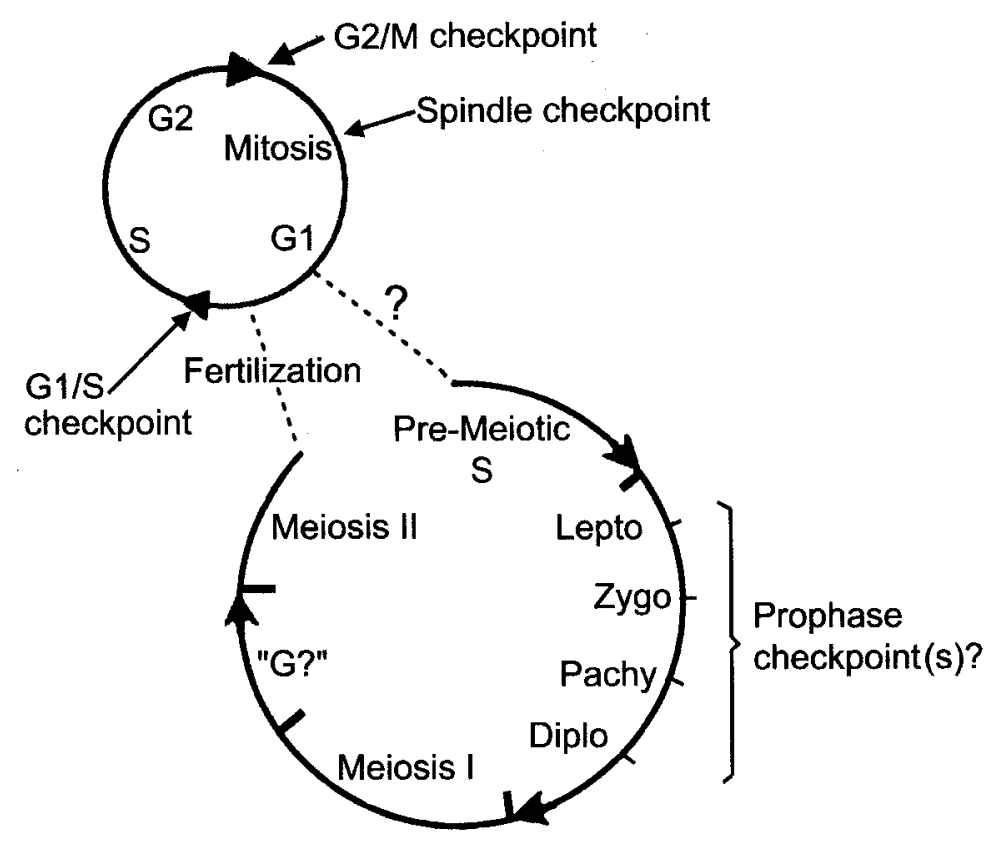

FIG. 4. Possible restriction points during mitosis and meiosis.

anaphase is delayed in spermatocytes that are either colchicine treated or contain misaligned chromosomes (Rebollo and Gonzalez, 2000).

\section{Which of the Cell-cycle Components Are Expressed in the Testis?}

\section{A. OVERVIEW OF THE EXPERIMENTS}

We initiated our studies on identifying the cell-cycle genes involved in mammalian gametogenesis with a very simple hypothesis having two major points: 1) meiosis is a highly conserved process across organisms, thus the regulatory components may also be conserved; and 2) control points exists in mammalian meiosis that simply do not exist in lower forms, hence, novel cell-cycle regulators may have evolved to fulfill these specialized functions. As will be discussed in the following sections, both parts of this hypothesis have been shown to be true.

\section{B. SUMMARY OF CELL-CYCLE GENES EXPRESSED IN THE GERM LINE}

A variety of experimental approaches have been used to identify cellcycle genes expressed during gametogenesis, from mRNA expression and 
TABLE I

Genetic Models in Male Mice Exhibiting Meiotic Prophase Arrest and Apoptosis

\begin{tabular}{|c|c|c|c|}
\hline Mutation & Arrest point & Synapsis phenotype & Reference \\
\hline A-myb & Early pachytene & Not reported & Toscani et al., 1997 \\
\hline Atm & Zygotene/early pachytene & Frequent asynapsis & Xu et al., 1996 \\
\hline Dmc1 & Zygotene/early pachytene & Asynapsis & Yoshida et al., 1998 \\
\hline Msh4 & Zygotene & $\begin{array}{l}\text { Frequent asynapsis; } \\
\text { Nonhomologous } \\
\text { pairing }\end{array}$ & Kneitz et al., 2000 \\
\hline Msh5 & Zygotene/early pachytene & $\begin{array}{l}\text { Frequent asynapsis; } \\
\text { Nonhomologous } \\
\text { pairing }\end{array}$ & Edelmann et al., 1999 \\
\hline Scp3 & Zygotene & Asynapsis & Yuan et al., 2000 \\
\hline Spo11 & Zygotene & Asynapsis & $\begin{array}{l}\text { Baudat et al., 2000; } \\
\text { Romanienko and } \\
\text { Camerini-Otero, } 2000\end{array}$ \\
\hline XSxr(a)0 & Late prophase/meiosis I & $\begin{array}{l}\text { Asynapsis of the sex } \\
\text { chromosome }\end{array}$ & Odorisio et al., 1998 \\
\hline Hsp70.2 & Late pachytene & Failure to desynapse & Dix et al., 1997 \\
\hline Mlh1 & Late pachytene & Failure to desynapse & Edelmann et al., 1996 \\
\hline Cyclin A1 & Late pachytene/diplotene & Incomplete desynapsis & D. Liu et al., 1998 \\
\hline
\end{tabular}

protein analysis using several methods and known probes and reagents to screens to identify new genes. A summary of the overall expression patterns of various categories of cell-cycle regulators that have been investigated in our lab is presented in Figure 5. It should be recognized that the data were obtained from studies in the rodent model system, where precise identification of cell types is easier than in other mammals (e.g., humans). However, in several studies, we have been able to extend the expression analysis to humans. For example, cyclin A1 is expressed in human late pachytene to diplotene spermatocytes, very much as it is in the mouse (C. Liao, S.Q. Li, S. Mulrad, X.Y. Wang, and D.J. Wolgemuth, submitted).

The genes examined generally fall into four classes. First, genes that are expressed in both germline and somatic cells of gonads and are rather ubiquitously expressed in other cells. Second, genes that are much more abundant in the germ line and third, those that are apparently specific to the germ line. Finally, 

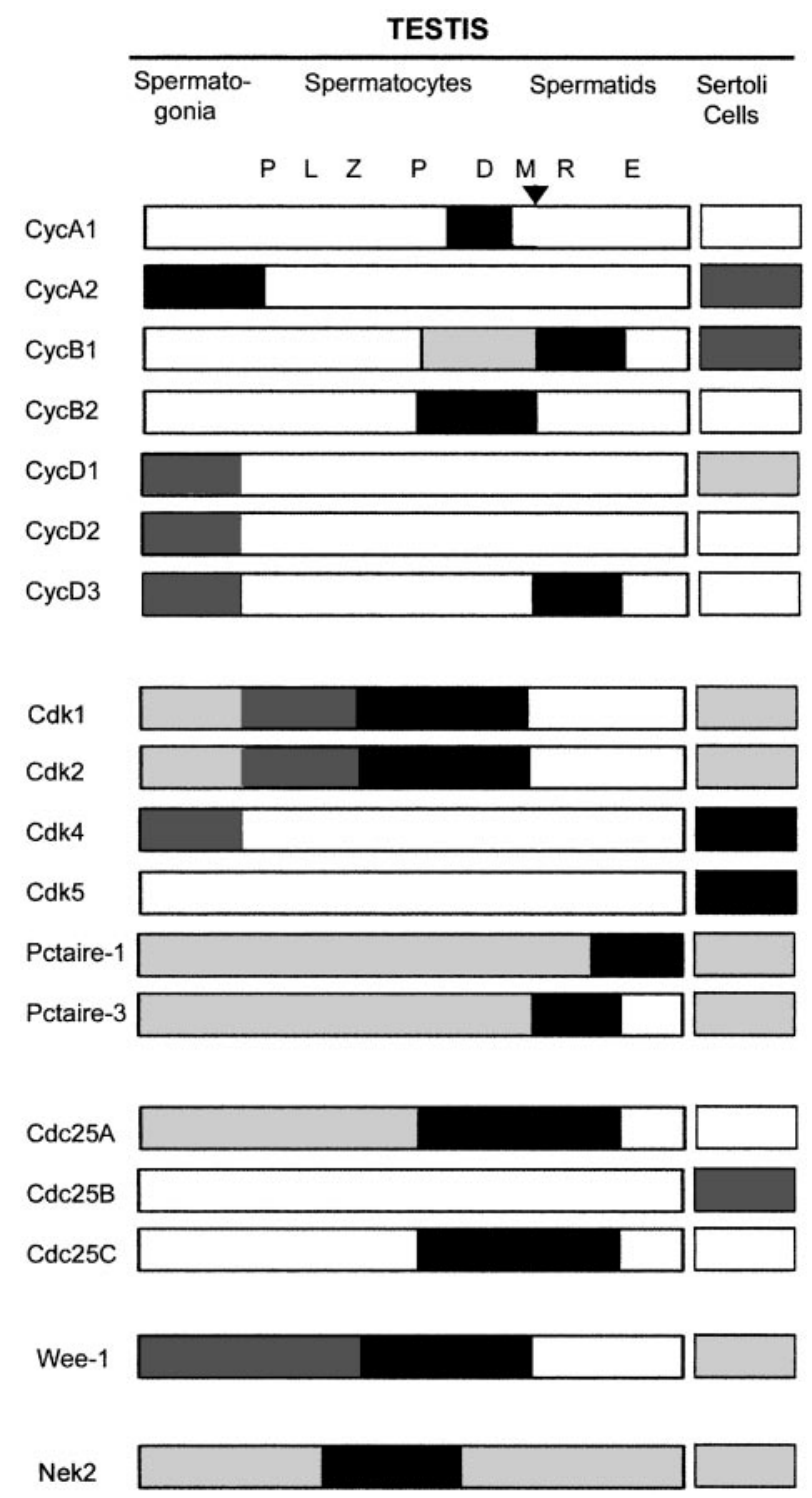

FIG. 5. Summary of the expression of selected cell-cycle-regulating genes in the mouse testis and ovary. This figure represents a composite of the results of studies from our laboratory on the levels of expression of the genes denoted on the left. The references containing the data supporting this compilation may be found in a review by Wolgemuth et al. (1995) and in references cited in this review. The relative levels of expression are depicted by shading of the bars: solid black, most robust expression of a particular gene; white bar, no detection of expression. 
genes that are specific to one or the other germ line (i.e., exhibiting sexual dimorphism in their patterns of expression).

\section{HIGHLIGHTS AND INTERESTING FEATURES OF THESE EXPRESSION PATTERNS THAT MAY BE IMPORTANT FOR SPERMATOGENESIS}

One of the earliest observations of unique differences between meiotic and somatic cells came from the observations of expression of the B-type cyclins (Chapman and Wolgemuth, 1992). The two mammalian B-type cyclins had been shown to be coexpressed in virtually all cultured cells analyzed. Surprisingly, their expression at the mRNA level was shown to be uncoupled in prophase spermatocytes. Cyclin B2 transcripts were detected earlier in prophase, at about the zygotene to early pachytene stage, and were followed by the appearance of cyclin B1 later in prophase. Further, cyclin B1 transcripts were observed in early round spermatids, which are postmeiotic. Whether these transcripts have any functional significance is not known, since subsequent studies using highly specific antibodies against the two B-type cyclins did not reveal significant accumulation of B1 protein in spermatids (Brandeis et al., 1998; D. Liu et al., 1998). The cyclin B1 null mutation results in embryonic lethality (Brandeis et al., 1998), thus obviating a direct test of its function in early spermatids in the adult. In contrast, cyclin B2 does not appear to be essential in that cyclin B2 knockout animals are viable and fertile, although a bit smaller and yielding slightly reduced litter sizes (Brandeis et al., 1998).

Another curiosity is the expression of cell-cycle genes, which are intimately tied to proliferation in mitotic cells, in testicular cells that are not dividing. In addition to the detection of cyclin B1 in spermatids, several of the Cdks have been observed to be expressed in nondividing cells in the testis. For example, both Cdk4 (Rhee and Wolgemuth, 1997) and Cdk5 (Q. Zhang, K. Rhee, and D.J. Wolgemuth, unpublished observations; Session et al., 2001) have been shown to be expressed in Sertoli cells in the adult mouse and human testis - cells that are no longer dividing and are highly differentiated.

Although the cyclins and Cdks are the major focus of this review, other pathways, possibly acting in parallel with cyclin/Cdk complexes, could play roles in mitosis and possibly in meiosis. For example, we and others have investigated the role of the putative homologues of the Aspergillus never in mitosis (NimA) gene (Osmani et al., 1991; Rhee and Wolgemuth, 1997; reviewed in Fry and Nigg, 1995). Although there appears to be as many as seven mammalian homologues of NimA (designated Nek genes), based on structural similarities, none has been shown to complement NimA in vivo (Schultz and Nigg, 1993; Kandli et al., 2000;). The pattern of expression of Nek1 and Nek2, in particular, during mammalian gametogenesis strongly 
suggests roles in meiosis (Letwin et al., 1992; Rhee and Wolgemuth, 1997; Tanaka et al., 1997; Arama et al., 1998).

\section{Focus on the A-type Cyclins}

\section{A. IDENTIFICATION OF TWO A-TYPE CYCLINS IN HIGHER ORGANISMS}

Of the mammalian cyclins identified to date, cyclin A has remained somewhat enigmatic, in part due to the fact that no homologues exist in the yeasts. We have shown that there are two distinct cyclin A genes in mammals, one of which, cyclin A1, is most highly expressed in the testis where it is restricted to the germ line (Ravnik and Wolgemuth, 1996; Sweeney et al., 1996). In contrast, cyclin A2 was expressed in all tissues analyzed. Two A-type cyclin genes have been documented in human and frog (Howe et al., 1995; Yang et al., 1997). Mouse cyclin A1 and A2 share 44\% identity at the amino acid level; however, they share a much higher level of identity (84\%) within the two highly conserved cyclin boxes (Ravnik and Wolgemuth, 1996; Sweeney et al., 1996).

\section{B. EXPRESSION OF THE A-TYPE CYCLINS IN MAMMALIAN GAMETOGENESIS}

In the adult mouse, Northern blot hybridization analysis revealed that expression of cyclin A1 was restricted to the testis, specifically, to meiotic germ cells. In situ hybridization analysis and immunohistochemistry were used to localize their expression to specific testicular cells. The levels of cyclin A1 mRNA (Sweeney et al., 1996; D. Liu et al., 1998) and protein (D. Liu et al., 1998; Ravnik and Wolgemuth, 1999) rise dramatically in late pachytene spermatocytes and become undetectable soon after completion of the first meiotic division. Thus, its expression is cell-cycle regulated. At both the RNA and protein levels, the predominant sites of cyclin A2 expression in the adult testis were the mitotic germ line stem cells, the spermatogonia, and in preleptotene spermatocytes, cells in which premeiotic DNA synthesis occurs (Ravnik and Wolgemuth, 1996,1999). Cyclin A2 expression also is detected in Leydig cells (Ge and Hardy, 1997). The concurrent localization of mRNA and protein for both of the A-type cyclins further suggested that both are regulated primarily at the level of transcription in the testis. The observed cellular specificity of cyclin A2 expression is consistent with its function during mitosis in the stem-cell stage of this lineage, while the restricted preleptotene stage localization suggests function in $\mathrm{G} 1 / \mathrm{S}$ or $\mathrm{S}$ but not in the meiotic divisions per se. No cyclin A1 mRNA was detected in ovaries or oocytes by Northern or in situ hybridization analysis (C. Liao, S.E. Ravnik, Q. Zhang, S. Mulrad, and D.J. Wolgemuth, in preparation). 
However, both somatic and germ cells of the adult ovary express cyclin A2 mRNA and protein. The different expression patterns suggest distinct functions for cyclin A1 and cyclin A2 in the somatic and germinal lineages, which also differ between the male and female.

Cyclin A2 is expressed ubiquitously in cultured cells and in a broad variety of tissues in the adult mouse and during embryogenesis (Ravnik and Wolgemuth, 1996; Sweeney et al., 1996). Perhaps not surprisingly then, targeted mutagenesis of encoding murine cyclin A2 resulted in early embryonic lethality, apparently around the peri-implantation stage (Murphy et al., 1997). This embryonic lethality has obviated understanding the role of cyclin A2 in other aspects of mammalian development, including the germ line. In contrast, the strikingly restricted expression of cyclin A1 led us to hypothesize that its primary site of function is in the male germ line, specifically, at the first meiotic division.

\section{REGULATION OF EXPRESSION OF THE A-TYPE CYCLINS}

Regulation of cyclin A2 has been extensively studied in cultured cells and shown to be first expressed during the mitotic cell cycle at the G1/S transition (reviewed in Pines and Hunter, 1991). The regulatory elements required for efficient cell-cycle-regulated transcription are contained within a small fragment of the proximal promoter ( 89 base pairs upstream and 11 base pairs downstream from its transcriptional start site) (Schulze et al., 1995). Periodic occupation of the CDE/CHR element, located in this fragment, by a repressor controls the timing of its expression (Zwicker et al., 1995b). Activities have been isolated from nuclear extracts that bind to the CDE/CHR (Liu et al., 1997) or to the CHR (Philips et al., 1999) in gel-shift experiments. E2F can bind the CDE of CDE/CHR (Zerfass-Thome et al., 1997). The CDE/CHR binding activity, termed CDE/CHR binding factor-1 (CDF-1), could not be supershifted by antibodies directed against E2F or DP-1 proteins. Mutating the first nucleotide of the CDE can abrogate E2F binding, while having little effect on the binding of CDF-1 in gel-shift experiments (N. Liu et al., 1998). The corresponding mutant reporter construct showed unchanged repression in G0, suggesting that E2F does not mediate repression of the gene for cyclin A2. This led to the hypothesis that E2F may compete with and displace CDF-1 in late G1/S phase, leading to transcriptional activation of the gene (N. Liu et al., 1998). Transcriptional activation upon E2F binding also can explain the observed upregulation of the cyclin A2 promoter following ectopic expression of E2F-1 (Schulze et al., 1995). The CHR-binding activity, CHR-binding factor (CHF), was isolated from nuclear extract from quiescent cells (Philips et al., 1999). CHF, when microinjected into cells, was able to downregulate the cyclin A2 promoter/reporter construct (Philips et al., 1999). 
It is speculated that the repressor occupying the CDE/CHR may interfere with the activity of factors bound upstream. In vivo footprinting revealed upstream elements that were protected constitutively during the cell cycle (Desdouets et al., 1995; Zwicker et al., 1995a). These elements bind Sp1, NF-Y, and CBP/cycA (CCAAT binding protein for cyclin A gene) and members of the ATF/CREB/CREM family (Desdouets et al., 1995; Zwicker et al., 1995a; Kramer et al., 1997). CBP/cycA is implicated in adhesion-dependent cyclin A2 transcription (Kramer et al., 1997), while members of ATF/CREB/CREM mediate regulation of the cyclin A2 promoter by cAMP (Desdouets et al., 1995). There may be cell specificity of binding of ATF/CREB/CREM family factors to the cAMP response element in the cyclin A2 promoter, as shown in gel-shift assays using extracts from various types of cells (Blanchard, 2000).

Almost nothing is known about the regulation of the cyclin A1 gene, especially in vivo. A 1.3-kb fragment of the human cyclin A1 promoter appears to reproduce the highly restricted tissue expression pattern in three of four transgenic mouse lines carrying human cyclin A1 reporter gene constructs (Muller et al., 2000a). Potential regulatory elements and factors that control expression have been studied in the context of a smaller promoter fragment that is comprised of 190 base pairs of upstream promoter sequence in cultured cells. This fragment can induce expression of a reporter gene mediated by GC boxes that can bind Sp1 in HeLa cells (Muller et al., 1999) and by coexpression with B-myb and cyclin A1 in CV-1 cells (Muller et al., 2000b). Although it was initially suggested that the tissue-specific expression of mouse cyclin A1 correlates with methylation of its CpG-rich proximal promoter (Muller et al., 2000a), subsequent studies revealed that this is not likely (Muller-Tidow et al., 2001). Cyclin A1 frequently is overexpressed in human acute promyelocytic leukemia, a subtype of acute myeloid leukemia that is characterized by the presence of the PML-RAR $\alpha$ fusion protein (Yang et al., 1999). A recent study has suggested that PML-RAR $\alpha$ ectopically expressed in human myeloid leukemia cell lines led to induction of co-transfected human cyclin A1 promoter/reporter constructs with either 190 base pairs of promoter or with $1.3 \mathrm{~kb}$ (Muller et al., 2000b). Whether such constructs will be activated in myeloid cells in vivo remains to be determined, as does the question of whether these flanking regions are active in spermatocytes.

\section{PREFERENCE OF CDK PARTNER FOR THE A-TYPE CYCLINS IN TESTICULAR CELLS}

To extend our studies on the function of the A-type cyclins during meiosis in the male at the biochemical level, we examined the developmental and cellular distribution of their candidate cyclin-dependent kinase partners, Cdk1 and Cdk2, in the spermatogenic lineage (Ravnik and Wolgemuth, 1999). As noted previ- 
ously, immunohistochemical localization revealed that cyclin A1 is present only in male germ cells just prior to or during the first, but not the second, meiotic division. By contrast, cyclin A2 was expressed in spermatogonia and was most abundant in preleptotene spermatocytes, cells about to enter the meiotic pathway. Immunohistochemical detection of Cdk1 was most apparent in early pachytene spermatocytes, while staining intensity diminished in diplotene and meiotically dividing spermatocytes, the cells in which cyclin A1 expression was strongest. Cdk2 was highly expressed in all spermatocytes. Notably, in cells undergoing the meiotic reduction divisions, Cdk2 appeared to localize specifically to the chromatin. This was not the case for spermatogonia undergoing mitotic divisions. We also showed that, in the testis, cyclin A1 binds both Cdk1 and Cdk2 (Sweeney et al., 1996; D. Liu et al., 1998,2000). In contrast, cyclin A2 strongly preferred to bind to Cdk2 in testicular lysates. These results suggest that the A-type cyclins have differences in their partner preference and may exhibit unique target substrate specificity.

\section{E. TARGETED MUTAGENESIS OF CYCLIN A1}

To begin to address possible redundancy of the two A-type cyclin genes, we generated cyclin A1-deficient mice by targeted mutagenesis of the cyclin A1 gene (D. Liu et al., 1998). The remarkable restriction of cyclin A1 suggested a very specific function only at the G2/M transition of the first meiotic division. Cyclin A1-deficient males were sterile due to a block of spermatogenesis before the first meiotic division, whereas females were normal. Meiosis arrest in males lacking cyclin A1 was associated with increased germ-cell apoptosis and desynapsis abnormalities (D. Liu et al., 1998,2000). There was a striking reduction in the activation of MPF kinase at the end of meiotic prophase, although both Cdk1 and cyclin B proteins were present. Cyclin A1 is therefore essential for spermatocyte passage into the first meiotic division in male mice, a function that cannot be complemented by the concurrently expressed B-type cyclins.

We then explored the possibility that a cyclin A1-dependent process dictates the activation of MPF (D. Liu et al., 1998). There are several pieces of evidence in the literature that supported a role for A-type cyclins in the activation of MPF. Xenopus cyclin A1 is synthesized before cyclin B and accumulates as an active kinase complex (Minshull et al., 1990). Cyclin A1 bound to Cdk1 in Xenopus egg extracts is immediately active, independent of Cdc25 activity (Clarke et al., 1992). The addition of cyclin A1 into such cell-free extracts potentiated MPF activity (Devault et al., 1992). Further, blocking Cdk2 activity, either by 21 or by immunodepletion, prevented activation of MPF and mitosis in cultured cells (Guadagno and Newport, 1996).

We asked whether the expression of the B-type cyclins that comprise MPF was retained in cyclin A1-deficient spermatocytes (Liu et al., 2000). Both cyclin 
B1 and B2 proteins were readily detected, although their associated kinases were kept at inactive states. We then turned to an in vitro, short-term culture system developed by Handel and colleagues (Wiltshire et al., 1995) in which treatment of pachytene spermatocytes with the protein phosphatase type 1 and type $2 \mathrm{~A}$ inhibitor okadaic acid can induce premature chromosome condensation and entry into the first meiotic division. We asked if treatment of the arrested diplotene spermatocytes in cyclin A1-deficient testes could drive the cells into meiosis I and activate MPF activity. Indeed, okadaic acid treatment restored MPF activity and induced entry into $\mathrm{M}$ phase and the formation of overtly normally condensed chromosome bivalents (Figure 4), concomitant with hyperphosphorylation of Cdc25 proteins (Liu et al., 2000).

Conversely, inhibition of tyrosine phosphatases, including Cdc25s, by vanadate suppressed the okadaic acid-induced metaphase induction. The highest levels of $\mathrm{Cdc} 25 \mathrm{~A}$ and $\mathrm{Cdc} 25 \mathrm{C}$ expression and their subcellular localization during meiotic prophase coincide with that of cyclin A1. When overexpressed in HeLa cells, cyclin A1 coimmunoprecipitates with Cdc25A. Furthermore, the protein kinase complexes consisting of cyclin A1 and either $\mathrm{Cdk} 1$ or $\mathrm{Cdk} 2$ phosphorylate both Cdc25A and Cdc25C in vitro (Liu et al., 2000). These results suggest that, in normal meiotic male germ cells, cyclin A1 participates in the regulation of other protein kinases or phosphatases critical for the G2-M transition. In particular, it may be directly involved in the initial amplification of MPF through the activating phosphorylation on Cdc25 phosphatases (Figure 3).

\section{Unanswered Questions}

Our investigations on the role of the A-type cyclins in the development, differentiation, and function of the germ line have provided some clues as to their in vivo function; however, much remains to be elucidated. Outlined below are several of the questions we would like to address.

\section{A. IS CYCLIN A2 REQUIRED IN MITOSIS IN SPERMATOGONIA AND FOR PRELEPTOTENE DNA SYNTHESIS?}

The striking differences in the patterns of expression between cyclin A1 and cyclin A2 in spermatogenic cells suggested that they would have distinct functions (Ravnik and Wolgemuth, 1999). Our targeted mutagenesis of the cyclin A1 gene revealed the clear requirement for this gene, specifically in meiosis in the male but not in the female germ line. The role of cyclin A2 is more difficult to assess because, as shown very elegantly by Murphy et al. (1997), loss of cyclin A2 results in early embryonic lethality. Embryos lacking cyclin A2 can develop from the two-cell to blastocyst stage but then die (Winston et al., 2000). Therefore, to study its function during spermatogenesis in the adult animal, a 
cell-specific targeted loss of function strategy will be needed. One such approach would involve the generation of transgenic mice expressing the Cre recombinase uniquely in spermatogonia and/or preleptotene spermatocytes, under the direction of a promoter specific to these cells. These animals would then be crossed to mice carrying the cyclin $\mathrm{A} 2$ gene into which loxP sites have been introduced (floxed cyclin A2). Excision of portions of the cyclin A2 gene between the loxP sites would result in a mutant cyclin A2 gene but only in spermatogonia or preleptotene spermatocytes. The critical missing link in this approach is the lack of well-characterized, spermatogonia-specific promoters.

\section{B. IS CYCLIN A2 ESSENTIAL FOR OOGENESIS?}

Ongoing studies in our lab and the work of others have shown that cyclin A2 is expressed in the mouse oocyte (Winston et al., 2000; C. Liao, S.E. Ravnik, Q. Zhang, S. Mulrad, and D.J. Wolgemuth, in preparation). As noted previously, the early embryonic lethality of the cyclin A2 null mutation (Murphy et al., 1997; Winston et al., 2000) obviates a direct test of its function in the germ line in either male or female. The Cre-lox strategies discussed earlier - using, in this case, oocyte-specific promoters to drive Cre recombinase - might be fruitful to address the role of cyclin A2 in oocyte mitosis and especially meiosis. Alternatively, the recent, very exciting application of double-stranded RNAs (RNAi) to interfere with gene expression in oocytes might permit a direct test of the cyclin A2 protein in the resumption of meiosis (Svoboda et al., 2000). In this approach, double-stranded RNAs for the c-mos proto-oncogene were shown to inhibit the translation of c-mos mRNA in a time- and concentration-dependent manner. Importantly, this inhibition resulted in parthenogenetic activation of the oocytes, similar to the phenotype observed in c-mos knockout mouse oocytes (Colledge et al., 1994; Hashimoto et al., 1994).

\section{ARE THE A-TYPE CYCLINS FUNCTIONALLY REDUNDANT?}

One hypothesis regarding the possible functional redundancy of the two mammalian A-type cyclin proteins is that they have essentially identical functions as part of cyclin $\mathrm{A} / \mathrm{Cdk}$ complexes and that differences in their function are reflected only by where they are expressed. A prediction of this hypothesis is that the two A-type cyclins would have identical biochemical properties as part of a Cdk1 or Cdk2 complex and be functionally interchangeable in vivo. An alternative hypothesis is that the two mammalian A-type cyclins have distinct functions as well as distinct regulation of expression. Yet a third possibility is that they may have both common and distinct functions, including unique functions of cyclin A1 in meiotic progression.

One approach for assessing these possibilities would ask whether functional differences between cyclin A1- and A2-containing kinase complexes can be 
detected with regard to their activity on specific substrates. One might also examine the interaction of cyclin A1 with proteins known to interact with cyclin A2 in vivo, including upstream inhibitors and activators and/or downstream targets. A systematic screen of known targets of cyclinA2/Cdk complexes for differences in the specificity of kinase activity of cyclin A1-containing versus cyclin A2-containing complexes might be quite informative. In such a scenario, particular attention would be paid to substrates whose expression and function, if known, might suggest a role during spermatogenesis.

A second strategy might utilize a molecular genetic approach to address the question of functional redundancy between the cyclin A1 and A2 proteins. As noted before, we have generated a targeted mutation in the cyclin A1 gene that resulted in an arrest in spermatogenesis specifically at the late pachytenediplotene stage of meiosis. The first meiotic division is prevented and the cells undergo a wave of apoptosis. One might now ask if cyclin A2 can rescue the meiotic arrest caused by the lack of cyclin A1 expression in the knockout mice. The use of either a transgenic approach using regulatory sequences that drive the expression of cyclin A1 to the appropriate cell types in vivo (K.M. Lele and D.J. Wolgemuth, unpublished observations) to drive coding sequences for cyclin A2 or alternatively, a knock-in approach (Hanks et al., 1995) could be envisioned. The technically more-complicated "knock-in" strategy would involve placing cyclin A2 coding sequences within the context of the cyclin A1 gene and then substituting into the genome by targeted mutagenesis.

\section{WHAT ARE THE SUBSTRATES FOR CYCLIN A1/CDK COMPLEXES IN GERM CELLS?}

As mentioned before, cyclin A2 functions during both G1-S and G2-M phases in cultured cells (Girard et al., 1991; Pagano et al., 1992; Pines and Hunter, 1994). The activity of the cyclin A2/Cdk2 kinase complex has been shown to be regulated by either inhibitory or activating proteins. Cyclin A2/Cdk2 shares some common properties with other G1/S or G2/M-phase cyclin/kinase complexes as well as possessing several features that are unique. Unlike cyclin B1, cyclin A2 can bind and activate both Cdk1 and Cdk2 proteins (Elledge et al., 1992; Kobayashi et al., 1992; Rosenblatt et al., 1992). While both cyclin A2/Cdk and cyclin $\mathrm{B} / \mathrm{Cdk} 1$ phosphorylate histone $\mathrm{H} 1$, only cyclin $\mathrm{A} 2 / \mathrm{Cdk}$ complexes were shown to associate with and phosphorylate the Rb-related protein p107 in vitro (Peeper et al., 1993). Differences in the consensus phosphorylation site for cyclin A2 versus cyclin E/Cdk2 complexes have been determined (Higashi et al., 1995). Cyclin A2/Cdk2 was more efficient than cyclin $\mathrm{E} / \mathrm{Cdk} 2$ in phosphorylating the transcription factor E2f-1 (Kitagawa et al., 1995). Cyclin A or E/Cdk2 and cyclin D/Cdk4 can all phosphorylate pRB; however, the phosphorylation sites are different (Kitagawa et al., 1996). Much less is known about cyclin A1, 
in particular as to how it may differ from cyclin A2 with respect to its interacting proteins and substrates. Our studies on the role of okadaic acid in overcoming the block in the first meiotic division in the absence of cyclin A1 led us to explore the role of the Cdc25 phosphatases as potential downstream targets of cyclin $\mathrm{A} 1 / \mathrm{Cdk}$. We previously had shown that $\mathrm{Cdc} 25 \mathrm{C}$ is expressed in late meiotic prophase cells in the mouse testis (Wu and Wolgemuth, 1995) and, recently, that Cdc25A is also expressed in spermatocytes at this stage (as is cyclin A1) (Liu et al., 2000). We have gone on to demonstrate that cyclin A1 can co-precipitate Cdc25A in co-transfection experiments and that testicular cyclin A1/Cdk2 kinase complexes can phosphorylate recombinant $\mathrm{Cdc} 25 \mathrm{~A}$ and $\mathrm{Cdc} 25 \mathrm{C}$ in vitro (Liu et al., 2000). Whether the Cdc25s are critical substrates in vivo in pachytene spermatocytes remains to be determined.

\section{E. WHAT ARE THE MECHANISMS BY WHICH THE LACK OF CYCLIN A1 TRIGGERS APOPTOSIS?}

A striking aspect of the loss of cyclin A1 function during male meiosis is the abrupt entry of the late-pachytene/diplotene spermatocytes into cell death or apoptosis, as assessed by TUNEL (terminal-deoxy UTP nick end labeling) assay (D. Liu et al., 1998). In fact, we have noted that apoptosis is characteristic of loss of function of several genes that have been shown by targeted mutagenesis to be required for the progression of meiotic prophase. Table I lists several of these genes and the stage at which the cells arrest. There are several pathways by which cells can undergo cell death, including pathways mediated by p53, members of the Bcl2/Bax family, Fas/Fas ligand, and the TNF-R superfamily (reviewed in Raff, 1998, and Strasser et al., 2000). A role for p53-mediated pathway in the apoptosis observed in Atm-deficient spermatocytes is suggested by the elevated levels of p53, Bax, and p21 observed in Atm-deficient testes and the decrease in apoptosis seen in mice lacking both Atm and 553 function (Barlow et al., 1997). There was not a complete loss of apoptosis, however, which raises the possibility of multiple pathways. The pathways of apoptosis for the other mutant strains listed in Table I remain to be elucidated.

\section{ACKNOWLEDGMENTS}

This work was supported in part by grants from the National Institutes of Health, HD34915 (DJW) and T32 DK07647 (KML). We thank former members of the Wolgemuth lab whose experimental and intellectual contributions helped to form the foundation on which our current and future studies on cell-cycle control are based. In particular, we wish to acknowledge Drs. Debbie Chapman, Kunsoo Rhee, Shuang Wu, Qi Zhang, Valerie Besset, Stuart Ravnik, Dong Liu, and Ching Liao. 


\section{REFERENCES}

Alberts B, Bray D, Lewis J, Raff M, Roberts K, Watson J 1983 Molecular Biology of the Cell. New York: Garland Publishing, Inc.

Arama E, Yanai A, Kilfin G, Bernstein A, Motro B 1998 Murine NIMA-related kinases are expressed in patterns suggesting distinct functions in gametogenesis and a role in the nervous system. Oncogene 16:1813-1823

Badie C, Itzhaki JE, Sullivan MJ, Carpenter AJ, Porter AC 2000 Repression of CDK1 and other genes with $\mathrm{CDE}$ and CHR promoter elements during DNA damage-induced $\mathrm{G}(2) / \mathrm{M}$ arrest in human cells. Mol Cell Biol 20:2358-2366

Barlow C, Liyanage M, Moens PB, Deng CX, Ried T, Wynshaw-Boris A 1997 Partial rescue of the prophase I defects of Atm-deficient mice by p53 and p21 null alleles. Nature Genet 17:462-466

Baudat F, Manova K, Yuen JP, Jasin M, Keeney S 2000 Chromosome synapsis defects and sexually dimorphic meiotic progression in mice lacking spo11. Mol Cell 6:989-998

Blanchard J 2000 Cyclin A2 transcriptional regulation: modulation of cell cycle control at the G1/S transition by peripheral cues. Biochem Pharmacol 60:1179-1184

Blasina A, Price BD, Turenne GA, McGowan CH 1999 Caffeine inhibits the checkpoint kinase ATM. Curr Biol 9:1135-1138

Brandeis M, Rosewell I, Carrington M, Crompton T, Jacobs MA, Kirk J, Gannon J, Hunt T 1998 Cyclin B2-null mice develop normally and are fertile whereas cyclin B1-null mice die in utero. Proc Natl Acad Sci USA 95:4344-4349

Bunz F, Dutriaux A, Lengauer C, Waldman T, Zhou S, Brown JP, Sedivy JM, Kinzler KW, Vogelstein B 1998 Requirement for p53 and p21 to sustain G2 arrest after DNA damage. Science 282:1497-1501

Chapman DL, Wolgemuth DJ 1992 Identification of a mouse B-type cyclin which exhibits developmentally regulated expression in the germ line. Mol Reprod Dev 33:259-269

Chapman DL, Wolgemuth DJ 1993 Isolation of the murine cyclin B2 cDNA and characterization of the lineage and temporal specificity of expression of the B1 and B2 cyclins during oogenesis, spermatogenesis and early embryogenesis. Development 118:229-240

Chapman DL, Wolgemuth DJ 1994 Expression of proliferating cell nuclear antigen in the mouse germ line and surrounding somatic cells suggests both proliferation-dependent and -independent modes of function. Intl J Dev Biol 38:491-497

Chesnel F, Eppig JJ 1995 Synthesis and accumulation of p34cdc2 and cyclin B in mouse oocytes during acquisition of competence to resume meiosis. Mol Reprod Dev 40:503-508

Clarke DJ, Gimenez-Abian JF 2000 Checkpoints controlling mitosis. Bioessays 22:351-363

Clarke PR, Leiss D, Pagano M, Karsenti E 1992 Cyclin A- and cyclin B-dependent protein kinases are regulated by different mechanisms in Xenopus egg extracts. EMBO J 11:1751-1761

Colledge WH, Carlton MB, Udy GB, Evans MJ 1994 Disruption of c-mos causes parthenogenetic development of unfertilized mouse eggs [see comments]. Nature 370:65-68

den Elzen N, Pines J 2001 Cyclin a is destroyed in prometaphase and can delay chromosome alignment and anaphase. J Cell Biol 153:121-136

Desdouets C, Matesic G, Molina CA, Foulkes NS, Sassone-Corsi P, Brechot C, Sobczak-Thepot J 1995 Cell cycle regulation of cyclin A gene expression by the cyclic AMP-responsive transcription factors CREB and CREM. Mol Cell Biol 15:3301-3309

Devault A, Fesquet D, Cavadore JC, Garrigues AM, Labbe JC, Lorca T, Picard A, Philippe M, Doree M 1992 Cyclin A potentiates maturation-promoting factor activation in the early Xenopus embryo via inhibition of the tyrosine kinase that phosphorylates cdc2. J Cell Biol 118:1109-1120 
Dix DJ, Allen JW, Collins BW, Poorman-Allen P, Mori C, Blizard DR, Brown PR, Goulding EH, Strong BD, Eddy EM 1997 HSP70-2 is required for desynapsis of synaptonemal complexes during meiotic prophase in juvenile and adult mouse spermatocytes. Development 124:4595-4603

Edelmann W, Cohen PE, Kane M, Lau K, Morrow B, Bennett S, Umar A, Kunkel T, Cattoretti G, Chaganti R, Pollard JW, Kolodner RD, Kucherlapati R 1996 Meiotic pachytene arrest in MLH1-deficient mice. Cell 85:1125-1134

Edelmann W, Yang K, Kuraguchi M, Heyer J, Lia M, Kneitz B, Fan K, Brown AM, Lipkin M, Kucherlapati R 1999 Tumorigenesis in Mlh1 and Mlh1/Apc1638N mutant mice. Cancer Res 59:1301-1307

Elledge SJ, Harper JW 1998 The role of protein stability in the cell cycle and cancer. Biochim Biophys Acta 1377:M61-M70

Elledge SJ, Richman R, Hall FL, Williams RT, Lodgson N, Harper JW 1992 CDK2 encodes a $33-\mathrm{kDa}$ cyclin A-associated protein kinase and is expressed before CDC2 in the cell cycle. Proc Natl Acad Sci USA 89:2907-2911

Fry AM, Nigg EA 1995 Cell cycle. The NIMA kinase joins forces with Cdc2. Curr Biol 5:1122-1125

Gallant P, Nigg EA 1992 Cyclin B2 undergoes cell cycle-dependent nuclear translocation and, when expressed as a non-destructible mutant, causes mitotic arrest in HeLa cells. J Cell Biol 117:213-224

Ge RS, Hardy MP 1997 Decreased cyclin A2 and increased cyclin G1 levels coincide with loss of proliferative capacity in rat Leydig cells during pubertal development. Endocrinology 138: 3719-3726

Girard F, Strausfeld U, Fernandez A, Lamb NJ 1991 Cyclin A is required for the onset of DNA replication in mammalian fibroblasts. Cell 67:1169-1179

Guadagno TM, Newport JW 1996 Cdk2 kinase is required for entry into mitosis as a positive regulator of Cdc2-cyclin B kinase activity. Cell 84:73-82

Hanks M, Wurst W, Anson-Cartwright L, Auerbach AB, Joyner AL 1995 Rescue of the En-1 mutant phenotype by replacement of En-1 with En-2 [see comments]. Science 269:679-682

Hashimoto N, Watanabe N, Furuta Y, Tamemoto H, Sagata N, Yokoyama M, Okazaki K, Nagayoshi M, Takeda N, Ikawa Y 1994 Parthenogenetic activation of oocytes in c-mosdeficient mice. Nature 370:68-71

Hershko A, Ciechanover A 1998 The ubiquitin system. Annu Rev Biochem 67:425-479

Higashi H, Suzuki-Takahashi I, Taya Y, Segawa K, Nishimura S, Kitagawa M 1995 Differences in substrate specificity between Cdk2-cyclin A and Cdk2-cyclin E in vitro. Biochem Biophys Res Commun 216:520-525

Hoffmann I, Clarke PR, Marcote MJ, Karsenti E, Draetta G 1993 Phosphorylation and activation of human cdc25-C by cdc2-cyclin B and its involvement in the self-amplification of MPF at mitosis. EMBO J 12:53-63

Howe JA, Howell M, Hunt T, Newport JW 1995 Identification of a developmental timer regulating the stability of embryonic cyclin A and a new somatic A-type cyclin at gastrulation. Genes Dev 9:1164-1176

Kakizuka A, Sebastian B, Borgmeyer U, Hermans-Borgmeyer I, Bolado J, Hunter T, Hoekstra MF, Evans RM 1992 A mouse cdc25 homolog is differentially and developmentally expressed. Genes Dev 6:578-590

Kandli M, Feige E, Chen A, Kilfin G, Motro B 2000 Isolation and characterization of two evolutionarily conserved murine kinases (Nek6 and nek7) related to the fungal mitotic regulator, NIMA. Genomics 68:187-196

Kitagawa M, Higashi H, Suzuki-Takahashi I, Segawa K, Hanks SK, Taya Y, Nishimura S, Okuyama A 1995 Phosphorylation of E2F-1 by cyclin A-cdk2. Oncogene 10:229-236 
Kitagawa M, Higashi H, Jung HK, Suzuki-Takahashi I, Ikeda M, Tamai K, Kato J, Segawa K, Yoshida E, Nishimura S, Taya Y 1996 The consensus motif for phosphorylation by cyclin D1-Cdk4 is different from that for phosphorylation by cyclin A/E-Cdk2. EMBO J 15:70607069

Kneitz B, Cohen PE, Avdievich E, Zhu L, Kane MF, Hou H Jr, Kolodner RD, Kucherlapati R, Pollard JW, Edelmann W 2000 MutS homolog 4 localization to meiotic chromosomes is required for chromosome pairing during meiosis in male and female mice. Genes Dev 14:1085-1097

Kobayashi H, Stewart E, Poon R, Adamczewski JP, Gannon J, Hunt T 1992 Identification of the domains in cyclin A required for binding to, and activation of, p34cdc2 and $\mathrm{p} 32 \mathrm{cdk} 2$ protein kinase subunits. Mol Biol Cell 3:1279-1294

Kramer A, Carstens CP, Wasserman WW, Fahl WE 1997 CBP/cycA, a CCAAT-binding protein necessary for adhesion-dependent cyclin A transcription, consists of NF-Y and a novel $\mathrm{Mr}$ 115,000 subunit. Cancer Res 57:5117-5121

Lange-zu Dohna C, Brandeis M, Berr F, Mossner J, Engeland K 2000 A CDE/CHR tandem element regulates cell cycle-dependent repression of cyclin B2 transcription. FEBS Lett 484:77-81

Le Cam L, Polanowska J, Fabbrizio E, Olivier M, Philips A, Ng Eaton E, Classon M, Geng Y, Sardet C 1999 Timing of cyclin E gene expression depends on the regulated association of a bipartite repressor element with a novel E2F complex. EMBO J 18:1878-1890

Letwin K, Mizzen L, Motro B, Ben-David Y, Bernstein A, Pawson T 1992 A mammalian dual specificity protein kinase, Nek1, is related to the NIMA cell cycle regulator and highly expressed in meiotic germ cells. EMBO J 11:3521-3531

Li J, Meyer AN, Donoghue DJ 1995 Requirement for phosphorylation of cyclin B1 for Xenopus oocyte maturation. Mol Biol Cell 6:1111-1124

Liu D, Matzuk MM, Sung WK, Guo Q, Wang P, Wolgemuth DJ 1998 Cyclin A1 is required for meiosis in the male mouse. Nature Genet 20:377-380

Liu D, Liao C, Wolgemuth DJ 2000 A role for cyclin A1 in the activation of MPF and G2-M transition during meiosis of male germ cells in mice. Dev Biol 224:388-400

Liu N, Lucibello FC, Korner K, Wolfraim LA, Zwicker J, Muller R 1997 CDF-1, a novel E2F-unrelated factor, interacts with cell cycle-regulated repressor elements in multiple promoters. Nucleic Acids Res 25:4915-4920

Liu N, Lucibello FC, Engeland K, Muller R 1998 A new model of cell cycle-regulated transcription: repression of the cyclin A promoter by CDF-1 and anti-repression by E2F. Oncogene 16:2957-2963

Lopez-Girona A, Kanoh J, Russell P 2001 Nuclear exclusion of Cdc25 is not required for the DNA damage checkpoint in fission yeast. Curr Biol 11:50-54

Mailand N, Falck J, Lukas C, Syljuasen RG, Welcker M, Bartek J, Lukas J 2000 Rapid destruction of human Cdc25A in response to DNA damage. Science 288:1425-1429

Manni I, Mazzaro G, Gurtner A, Mantovani R, Haugwitz U, Krause K, Engeland K, Sacchi A, Soddu S, Piaggio G 2001 NF-Y mediates the transcriptional inhibition of the cyclin B1, cyclin B2, and cdc25C promoters upon induced G2 arrest. J Biol Chem 276:5570-5576

Masui Y, Markert CL 1971 Cytoplasmic control of nuclear behavior during meiotic maturation of frog oocytes. J Exp Zool 177:129-145

Mendez R, Richter JD 2001 Translational control by CPEB: a means to the end. Nature Rev Mol Cell Biol 2:521-529

Minshull J, Golsteyn R, Hill CS, Hunt T 1990 The A- and B-type cyclin associated cdc2 kinases in Xenopus turn on and off at different times in the cell cycle. EMBO J 9:2865-2875

Muller C, Yang R, Beck-von-Peccoz L, Idos G, Verbeek W, Koeffler HP 1999 Cloning of the cyclin A1 genomic structure and characterization of the promoter region. GC boxes are 
essential for cell cycle-regulated transcription of the cyclin A1 gene. J Biol Chem 274:1122011228

Muller C, Readhead C, Diederichs S, Idos G, Yang R, Tidow N, Serve H, Berdel WE, Koeffler HP 2000a Methylation of the cyclin A1 promoter correlates with gene silencing in somatic cell lines, while tissue-specific expression of cyclin A1 is methylation independent. Mol Cell Biol 20:3316-3329

Muller C, Yang R, Park DJ, Serve H, Berdel WE, Koeffler HP 2000b The aberrant fusion proteins PML-RAR alpha and PLZF-RAR alpha contribute to the overexpression of cyclin A1 in acute promyelocytic leukemia. Blood 96:3894-3899

Muller-Tidow C, Bornemann C, Diederichs S, Westermann A, Klumpen S, Zuo P, Wang W, Berdel WE, Serve H 2001 Analyses of the genomic methylation status of the human cyclin A1 promoter by a novel real-time PCR-based methodology. FEBS Lett 490:75-78

Murphy M, Stinnakre MG, Senamaud-Beaufort C, Winston NJ, Sweeney C, Kubelka M, Carrington M, Brechot C, Sobczak-Thepot J 1997 Delayed early embryonic lethality following disruption of the murine cyclin A2 gene [published erratum appears in Nature Genet 1999 23(4):481]. Nature Genet 15:83-86

Nargi JL, Woodford-Thomas TA 1994 Cloning and characterization of a cdc25 phosphatase from mouse lymphocytes. Immunogenetics 39:99-108

Odorisio T, Rodriguez TA, Evans EP, Clarke AR, Burgoyne PS 1998 The meiotic checkpoint monitoring synapsis eliminates spermatocytes via p53-independent apoptosis. Nature Genet 18:257-261

Osmani AH, McGuire SL, Osmani SA 1991 Parallel activation of the NIMA and p34cdc2 cell cycle-regulated protein kinases is required to initiate mitosis in A. nidulans. Cell 67:283-291

Pagano M, Pepperkok R, Verde F, Ansorge W, Draetta G 1992 Cyclin A is required at two points in the human cell cycle. EMBO J 11:961-971

Peeper DS, Parker LL, Ewen ME, Toebes M, Hall FL, Xu M, Zantema A, van der Eb AJ, Piwnica-Worms H 1993 A- and B-type cyclins differentially modulate substrate specificity of cyclin-cdk complexes. EMBO J 12:1947-1954

Philips A, Chambeyron S, Lamb N, Vie A, Blanchard JM 1999 CHF: a novel factor binding to cyclin A CHR corepressor element. Oncogene 18:6222-6232

Pines J 1995a Cyclins and cyclin-dependent kinases: a biochemical view. Biochem J 308:697-711

Pines J 1995b Cyclins, CDKs and cancer. Semin Cancer Biol 6:63-72

Pines J, Hunter T 1991 Human cyclins A and B1 are differentially located in the cell and undergo cell cycle-dependent nuclear transport. J Cell Biol 115:11-17

Pines J, Hunter T 1994 The differential localization of human cyclins A and B is due to a cytoplasmic retention signal in cyclin B. EMBO J 13:3772-3781

Pyronnet S, Dostie J, Sonenberg N 2001 Suppression of cap-dependent translation in mitosis. Genes Dev 15:2083-2093

Raff M 1998 Cell suicide for beginners. Nature 396:119-122

Ravnik SE, Wolgemuth DJ 1996 The developmentally restricted pattern of expression in the male germ line of a murine cyclin A, cyclin A2, suggests roles in both mitotic and meiotic cell cycles. Dev Biol 173:69-78

Ravnik SE, Wolgemuth DJ 1999 Regulation of meiosis during mammalian spermatogenesis: the A-type cyclins and their associated cyclin-dependent kinases are differentially expressed in the germ-cell lineage. Dev Biol 207:408-418

Ravnik SE, Rhee K, Wolgemuth DJ 1995 Distinct patterns of expression of the D-type cyclins during testicular development in the mouse. Dev Genet 16:171-178

Rebollo E, Gonzalez C 2000 Visualizing the spindle checkpoint in Drosophila spermatocytes. EMBO Rep 1:65-70 
Rhee K, Wolgemuth DJ 1997 The NIMA-related kinase 2, Nek2, is expressed in specific stages of the meiotic cell cycle and associates with meiotic chromosomes. Development 124:21672177

Rieder CL, Schultz A, Cole R, Sluder G 1994 Anaphase onset in vertebrate somatic cells is controlled by a checkpoint that monitors sister kinetochore attachment to the spindle. J Cell Biol 127:1301-1310

Roberts JM 1999 Evolving ideas about cyclins. Cell 98:129-132

Roeder GS, Bailis JM 2000 The pachytene checkpoint. Trends Genet 16:395-403

Romanienko PJ, Camerini-Otero RD 2000 The mouse spo11 gene is required for meiotic chromosome synapsis. Mol Cell 6:975-987

Rosenblatt J, Gu Y, Morgan DO 1992 Human cyclin-dependent kinase 2 is activated during the S and G2 phases of the cell cycle and associates with cyclin A. Proc Natl Acad Sci USA 89:2824-2828

Schultz SJ, Nigg EA 1993 Identification of 21 novel human protein kinases, including 3 members of a family related to the cell cycle regulator nimA of Aspergillus nidulans. Cell Growth Differ 4:821-830

Schulze A, Zerfass K, Spitkovsky D, Middendorp S, Berges J, Helin K, Jansen-Durr P, Henglein B 1995 Cell cycle regulation of the cyclin A gene promoter is mediated by a variant E2F site. Proc Natl Acad Sci USA 92:11264-11268

Schwartz D, Goldfinger N, Kam Z, Rotter V 1999 p53 controls low DNA damage-dependent premeiotic checkpoint and facilitates DNA repair during spermatogenesis. Cell Growth Differ 10:665-675

Session DR, Fautsch MP, Avula R, Jones WR, Nehra A, Wieben ED 2001 Cyclin-dependent kinase 5 is expressed in both Sertoli cells and metaphase spermatocytes. Fertil Steril 75:669-673

Sherr CJ 1993 Mammalian G1 cyclins. Cell 73:1059-1065

Sherr CJ, Roberts JM 1995 Inhibitors of mammalian G1 cyclin-dependent kinases. Genes Dev 9:1149-1163

Sherr CJ, Roberts JM 1999 CDK inhibitors: positive and negative regulators of G1-phase progression. Genes Dev 13:1501-1512

Stewart ZA, Pietenpol JA 2001 p53 Signaling and cell cycle checkpoints. Chem Res Toxicol $14: 243-263$

Strasser A, O'Connor L, Dixit VM 2000 Apoptosis signaling. Annu Rev Biochem 69:217-245

Svoboda P, Stein P, Hayashi H, Schultz RM 2000 Selective reduction of dormant maternal mRNAs in mouse oocytes by RNA interference. Development 127:4147-4156

Sweeney C, Murphy M, Kubelka M, Ravnik SE, Hawkins CF, Wolgemuth DJ, Carrington M 1996 A distinct cyclin A is expressed in germ cells in the mouse. Development 122:53-64

Taieb R, Thibier C, Jessus C 1997 On cyclins, oocytes, and eggs. Mol Reprod Dev 48:397-411

Tanaka K, Parvinen M, Nigg EA 1997 The in vivo expression pattern of mouse Nek2, a NIMA-related kinase, indicates a role in both mitosis and meiosis. Exp Cell Res 237:264-274

Toscani A, Mettus RV, Coupland R, Simpkins H, Litvin J, Orth J, Hatton KS, Reddy EP 1997 Arrest of spermatogenesis and defective breast development in mice lacking A-myb. Nature 386:713-717

Toyoshima F, Moriguchi T, Wada A, Fukuda M, Nishida E 1998 Nuclear export of cyclin B1 and its possible role in the DNA damage-induced G2 checkpoint. EMBO J 17:2728-2735

Wiltshire T, Park C, Caldwell KA, Handel MA 1995 Induced premature G2/M-phase transition in pachytene spermatocytes includes events unique to meiosis. Dev Biol 169:557-567

Winston N, Bourgain-Guglielmetti F, Ciemerych MA, Kubiak JZ, Senamaud-Beaufort C, Carrington M, Brechot C, Sobczak-Thepot J 2000 Early development of mouse embryos 
null mutant for the cyclin A2 gene occurs in the absence of maternally derived cyclin A2 gene products. Dev Biol 223:139-153

Wolgemuth DJ, Rhee K, Wu S, Ravnik SE 1995 Genetic control of mitosis, meiosis and cellular differentiation during mammalian spermatogenesis. Reprod Fertil Dev 7:669-683

Wu S, Wolgemuth DJ 1995 The distinct and developmentally regulated patterns of expression of members of the mouse Cdc25 gene family suggest differential functions during gametogenesis. Dev Biol 170:195-206

Xu Y, Ashley T, Brainerd EE, Bronson RT, Meyn MS, Baltimore D 1996 Targeted disruption of ATM leads to growth retardation, chromosomal fragmentation during meiosis, immune defects, and thymic lymphoma. Genes Dev 10:2411-2422

Yang J, Kornbluth S 1999 All aboard the cyclin train: subcellular trafficking of cyclins and their CDK partners. Trends Cell Biol 9:207-210

Yang R, Morosetti R, Koeffler HP 1997 Characterization of a second human cyclin A that is highly expressed in testis and in several leukemic cell lines. Cancer Res 57:913-920

Yang R, Nakamaki T, Lubbert M, Said J, Sakashita A, Freyaldenhoven BS, Spira S, Huynh V, Muller C, Koeffler HP 1999 Cyclin A1 expression in leukemia and normal hematopoietic cells. Blood 93:2067-2074

Yoshida K, Kondoh G, Matsuda Y, Habu T, Nishimune Y, Morita T 1998 The mouse RecA-like gene Dmc1 is required for homologous chromosome synapsis during meiosis. Mol Cell 1:707-718

Yuan L, Liu JG, Zhao J, Brundell E, Daneholt B, Hoog C 2000 The murine SCP3 gene is required for synaptonemal complex assembly, chromosome synapsis, and male fertility. Mol Cell 5:73-83

Zerfass-Thome K, Schulze A, Zwerschke W, Vogt B, Helin K, Bartek J, Henglein B, JansenDurr P 1997 p27KIP1 blocks cyclin E-dependent transactivation of cyclin A gene expression. Mol Cell Biol 17:407-415

Zwicker J, Gross C, Lucibello FC, Truss M, Ehlert F, Engeland K, Muller R 1995a Cell cycle regulation of cdc $25 \mathrm{C}$ transcription is mediated by the periodic repression of the glutaminerich activators NF-Y and Sp1. Nucleic Acids Res 23:3822-3830

Zwicker J, Lucibello FC, Wolfraim LA, Gross C, Truss M, Engeland K, Muller R 1995b Cell cycle regulation of the cyclin $\mathrm{A}, \mathrm{cdc} 25 \mathrm{C}$ and cdc2 genes is based on a common mechanism of transcriptional repression. EMBO J 14:4514-4522 